\title{
Improving building energy efficiency: a case study
}

\author{
S. Grignaffini, M. Romagna \& D. Principia \\ "Sapienza", University of Rome, Department of Astronautic, \\ Electric and Energetic Engineering, Italy
}

\begin{abstract}
The main purpose of this study was to conduct a study for improving energy efficiency of an important building in Rome, the Headquarters of the Italian State Monopoly. The study was conducted by comparing conventional analysis tools with innovative ones, in order to evaluate the possible solutions, both structural and plant, aimed at the use of renewable sources and at energy saving. After making a thermo graphic survey, the first and useful step for a good energy audit, conduct building energy was simulated, at first in steady state by the use of a software widely used at the professional level, then in transient state by the use of TRNSYS, a finite difference method software which is able to simulate more accurately conduct building energy. The next step was to propose possible redevelopment of a structural and energy plant that promotes the building energy rating higher, finding the right balance between the energetic and economic aspect. Among the interventions plant, two possible workarounds have been proposed and designed in detail:

- installation of a photovoltaic system;

- installation of a solar cooling system.

Both solutions lead to a reduction of electricity consumption with a significant impact in economic and environmental terms.
\end{abstract}

Keywords: energy efficiency, energy saving, steady state, transient state, photovoltaic system, solar cooling system.

\section{Introduction}

The work presented here has as its object the study of upgrading the energy efficiency of an important building in Rome the Headquarter of the Italian State 
Monopoly used primarily for office use. This study was performed by using two software programs that simulate the energy behaviour of the building, allow the calculation of energy losses and therefore the total energy demand in summertime and wintertime. The first software used, TFM-STIMA10 allowed us to perform the study of dispersion in steady state, following a conventional method, while the second one, TRNSYS16, simulates the energy behaviour in transient state. The work ends finally with the proposal of two engineering solutions that include the use of renewable resources: a photovoltaic system and, as an alternative to this, a solar cooling system.

\section{Analysis of the energy behaviour of the building before energy efficiency improvement}

\subsection{Thermographic survey}

As a first analysis tool of the energy behaviour of the building, thermography was used. A thermographic study may be an ideal tool to determine heat loss outside of a building, for the identification of sources of loss such as windows, doors, faulty insulation. By analyzing the radiation emitted by a body, you can identify thermal anomalies generated by losses or infiltrations both indoor and outdoor in order to reduce substantially energy costs. The identification of the cause of the defects or faults of a bad insulated building, lead to significant cost savings by intervening to repair the damage before it can become large or even irreparable.

Thermography is a "non-destructive" survey based on the principle that any body with a temperature greater than absolute zero emits energy in the form of electromagnetic radiation. The camera measures and displays the infrared radiation emitted by objects: this radiation resulting surface temperature of objects. Many other factors may affect the surveys: the emissivity, the radiation resulting from the environment and the absorption of radiation by the atmosphere.

Therefore, in order to accurately measure the temperature, it is necessary to offset the effects of a number of sources of radiation; so, in the measurement of absolute temperature, factors which can significantly distort the surveys should be considered: reflections of the surfaces, contact angle measurement, moisture, indoor temperature and emissivity of the measured area.

In the works of building renovation, energy saving is an issue of great topical interest. Thanks to thermography it is possible to determine the critical energy and structural points of buildings, clearly identifying the critical areas with significant thermal bridges (cold bridges). In fact, they constitute a privileged way to exchange heat to and from the outside. The main negative effects are the cooling of the areas closest, with the consequent creation of condensation and mildew with the reduction of the insulating properties of the walls.

It is very important in the energy redevelopment to precisely detect this type of problems, in order to provide interventions for energy saving. 


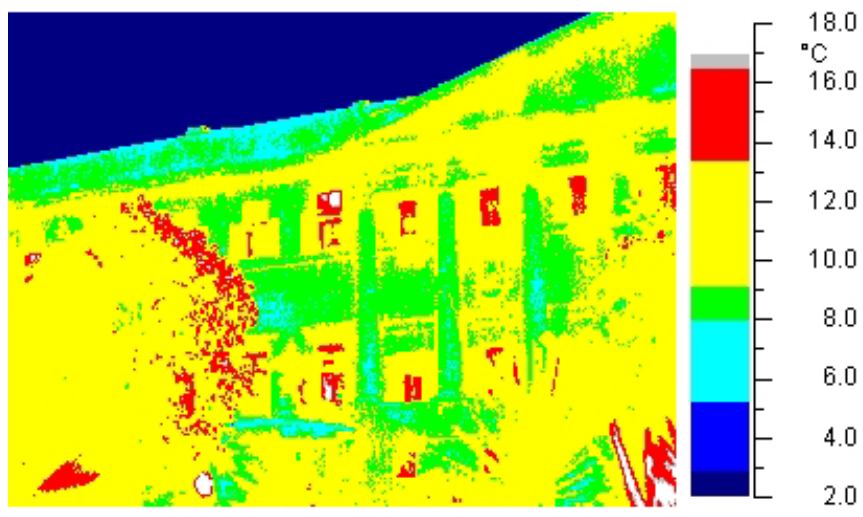

Figure 1: Thermographic image of the main facade of the building.

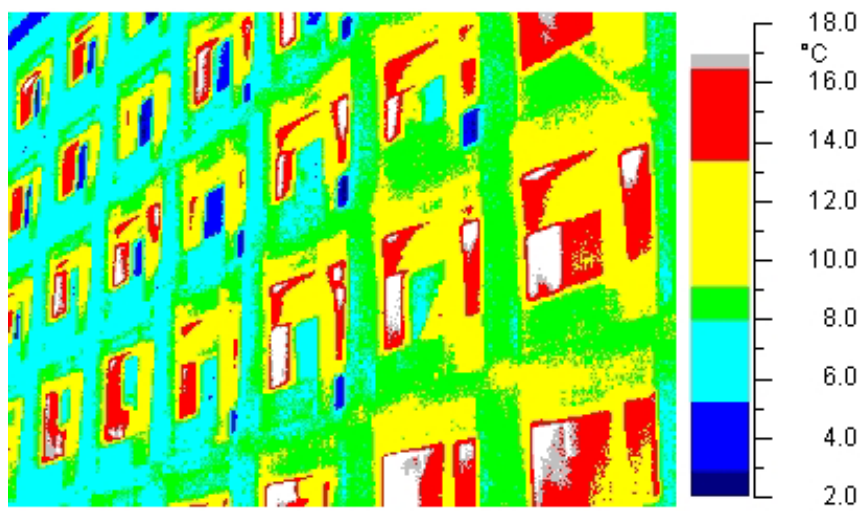

Figure 2: $\quad$ Thermographic image of the main facade of the building.

The images (Figures 1 and 2) obtained from camera show that the main cause of heat loss from the building envelope is to be attached to window frames.

\subsection{Steady state study}

At the first step, structures and systems that characterize the building had been identified, then the energy performance was simulated in steady state through the use of software STIMA-TFM. The building has the following features: seven floors above ground; average height of floor: $3 \mathrm{~m}$; area: $20.098 \mathrm{~m}^{2}$; volume: $60.295 \mathrm{~m}^{3}$ The software allows to create the heat dispersant structures (exterior walls, window frames, thermal bridges, floors) to be allocated to areas of the building; it consists essentially of a main spreadsheet (Figure 3) in which one we can describe the various rooms making up the building envelope (volume, dispersing facilities, ventilation and dispersion for transmission, etc..) and can automatically and sequentially to develop all the necessary operations, 


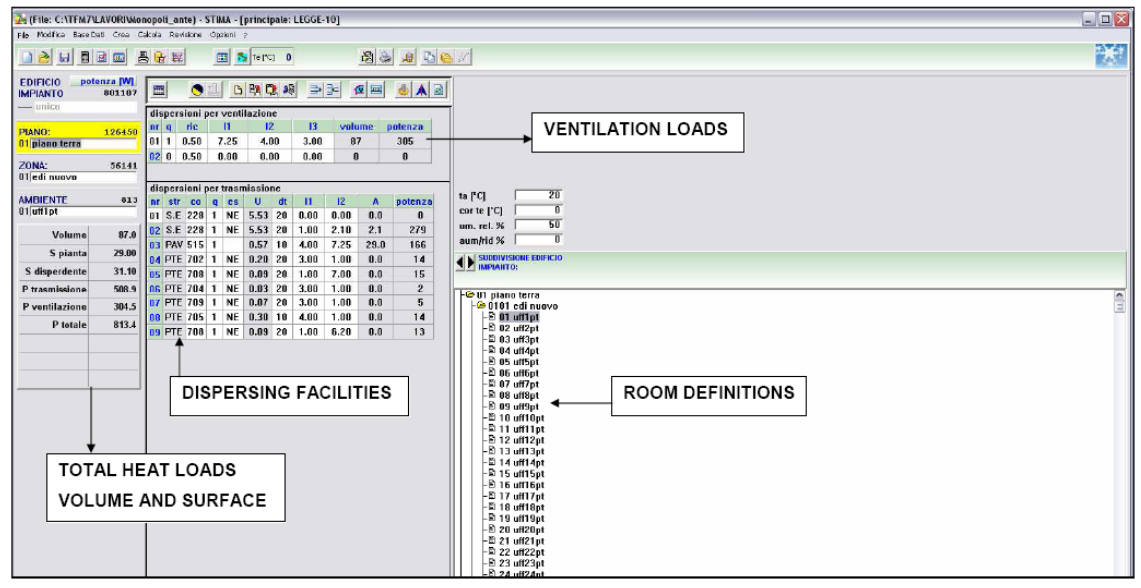

Figure 3: $\quad$ Main spreadsheet STIMA-TFM.

displaying results in real-time application of a series of procedures designed to support the methods of calculation for wintertime demand.

The results indicate a specific heating demand equal to $7.1 \mathrm{kWh} / \mathrm{m}^{3}$ year, a value that places the building envelope at " $\mathrm{D}$ " energy class according to the limits imposed by Italian legislation about the reduction of energy consumption and the use of energy efficiency in buildings (Figure 4).

The simulation allowed to highlight the main cause of heat loss is due to the window frames.

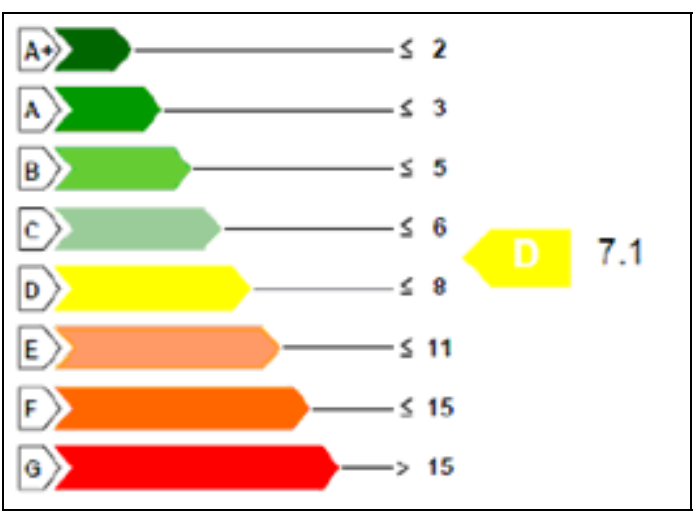

Figure 4: Building energy efficiency before energy efficiency improvement.

\subsection{Transient state study}

The energy performance of building was then simulated in transient state through the use of software TRNSYS16.

TRNSYS has a modular structure, consisting primarily of subroutines called "Types" written in Fortran language, allowing the inclusion of new mathematical 
models, not present in standard libraries, developed by users or interact with other programs like Excel and Mathlab. The Types are divided into 14 groups but conceptually can be divided into three main categories: the first group includes types with general function to conduct the simulation, such as a support for reading and writing data; then we have a group for data processing and finally a wide range of types that represent the mathematical model of a particular component, such as a solar collector, a tank, a solar panel, etc.. to be included in the simulation. Each of these subroutines describes the behaviour in a parametric way, and for each module specifying input, output and constant values. In a project in which useful Types are defined, we have to establish only the various connections each other according to the required syntax and mode of operation of the system to be simulated. At this point it is intuitive to exploit the modularity in order to reduce the complexity of the systems to be simulated, by dividing them into many easier sub problems. The operational phase described above, is expressed with the drafting of the input file "deck", where the connections between the various components constituting the system are specified. The "deck" file will be processed by TRNsys Simulation Processor called "TRNEdit". The type that describes buildings thermal model is "Type 56 or Multizone Building". This type, given the complexity of the model, requires the inclusion of many parameters and difficult syntax of the input file. However, using the application "TRNBuild" included in the software package, it is possible through an intuitive graphical interface, assigning the parameters in a much simplified way.

In case study proposed, simulation model is shown in Figure 5 with the assembly of different Types interconnected by boundary conditions on the variables of interest

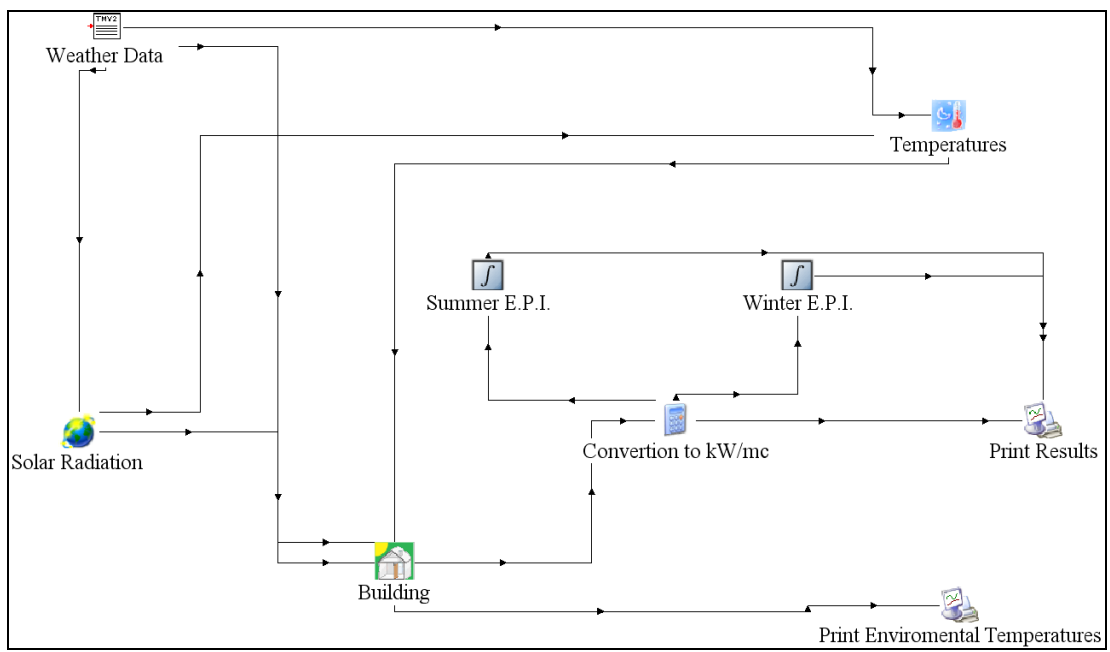

Figure 5: $\quad$ TRNsys16 simulation model. 
Given the large extension of the building, built in different ages with different construction technologies, the study was carried out by distinguishing two parts of the same: some older, known then as "Historic Building", and a part of building more recently, the "New Building".

So, two simulation models were compiled and a Type56 for each of which has been created: it was possible in this way to evaluate the annual energy needs of the building.

The results obtained from the simulation carried out are shown in Figures 6 and 7 .

The red curve represents the Heating Power demand $\left(\mathrm{kW} / \mathrm{m}^{3}\right)$ of the building (in winter), the blue one the Cooling Power demand $\left(\mathrm{kW} / \mathrm{m}^{3}\right)$ of the building (summer) (Figure 6).

Operating on an annual basis a mathematical integration of the powers mentioned above, you get the Winter Energy Performance Index ( $\mathrm{kWh} / \mathrm{m}^{3}$ year) (violet curve) and the Summer Energy Performance Index $\left(\mathrm{kWh} / \mathrm{m}^{3}\right.$ year) (yellow curve) (Figure 7).

The results obtained by the simulation indicate the Winter Energy Performance Index equal to $6.6 \mathrm{kWh} / \mathrm{m}^{3}$ year (value that places the building envelope at "D" energy class) and the Summer Energy Performance Index equal to $20 \mathrm{kWh} / \mathrm{m}^{3}$ year.

The red curve represents the Heating Power demand $\left(\mathrm{kW} / \mathrm{m}^{3}\right)$ of the building (in winter), the blue one the Cooling Power demand $\left(\mathrm{kW} / \mathrm{m}^{3}\right)$ of the building (summer) (Figure 6) .

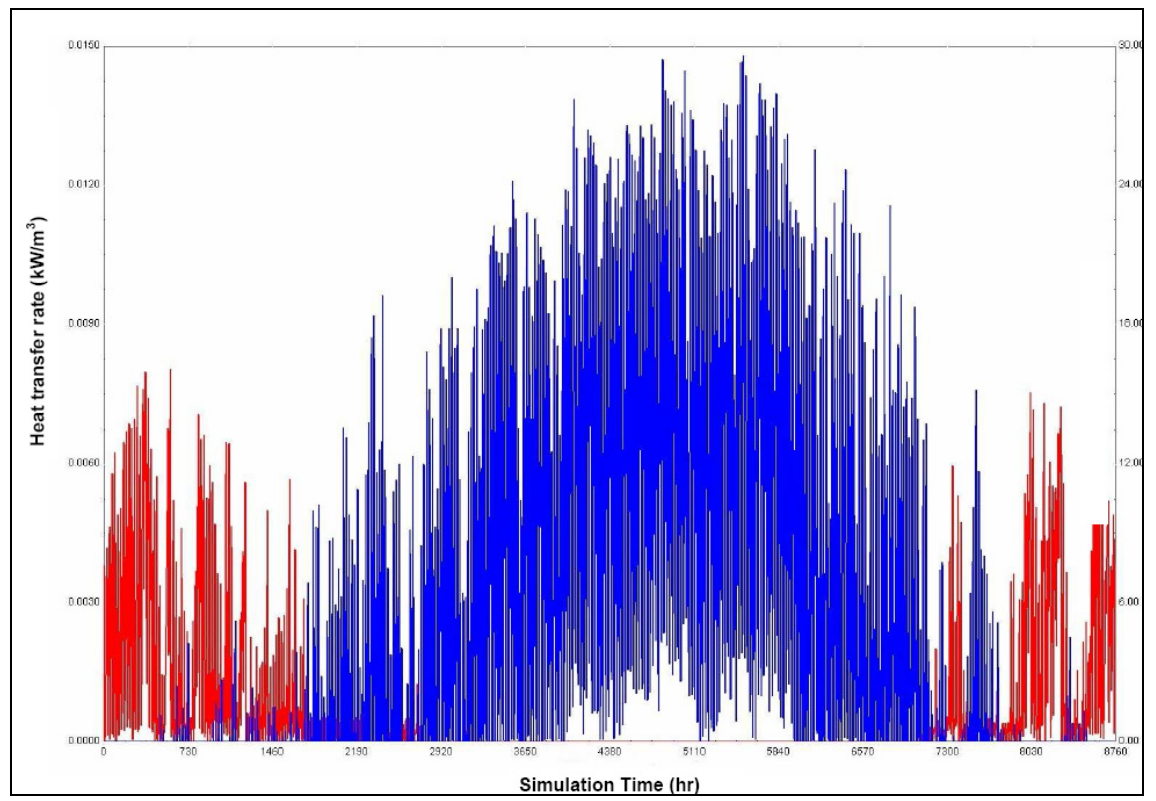

Figure 6: Heating and cooling power demand. 


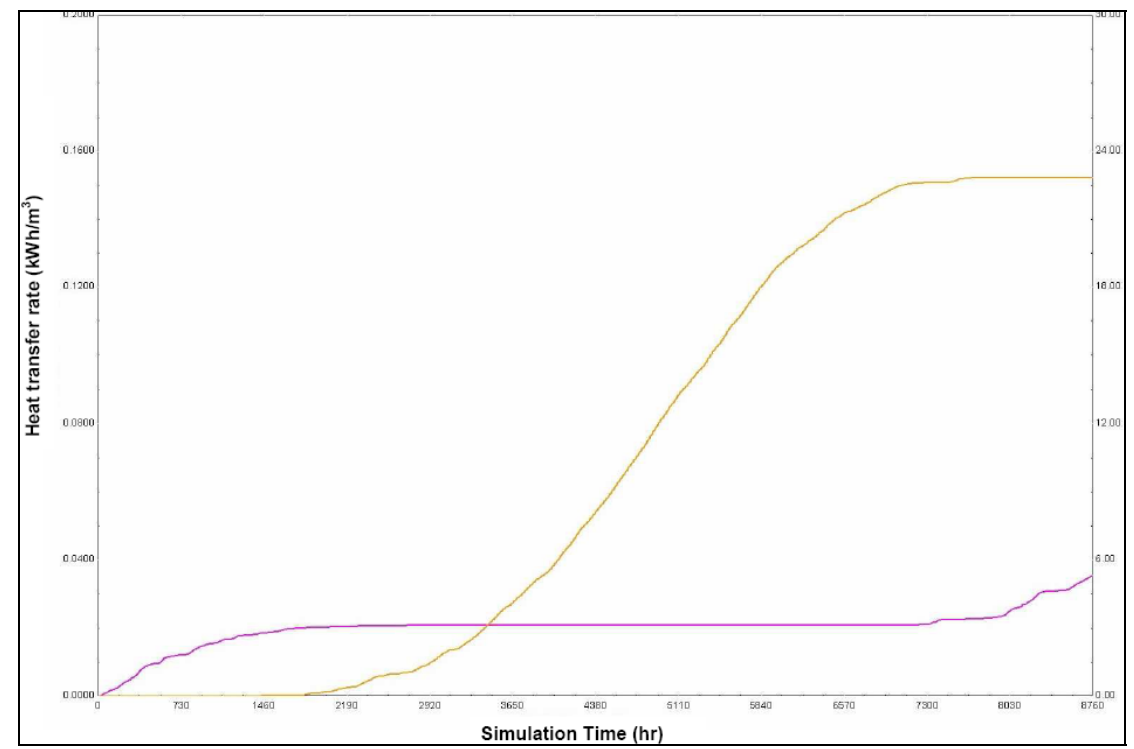

Figure 7: $\quad$ Energy performance indexes.

Operating on an annual basis a mathematical integration of the powers mentioned above, you get the Winter Energy Performance Index ( $\mathrm{kWh} / \mathrm{m}^{3}$ year) (violet (lower) curve) and the Summer Energy Performance Index ( $\mathrm{kWh} / \mathrm{m}^{3}$ year) (yellow (higher) curve) (Figure 7).

The results obtained by the simulation indicate the Winter Energy Performance Index equal to $6.6 \mathrm{kWh} / \mathrm{m}^{3}$ year (value that places the building envelope at " $\mathrm{D}$ " energy class) and the Summer Energy Performance Index equal to $20 \mathrm{kWh} / \mathrm{m}^{3}$ year.

\section{Interventions of energy efficiency upgrading}

Once the energy requirement or in other words, the energy consumption was established, the possible interventions aimed at upgrading the energy efficiency and at the reductions of the energy losses in order to promote the building to a higher energy class, have been proposed.

These interventions both structural and technological are the result of a choice of excellent between the factors and design constraints and the purely economic factors; they are listed below:

- Replacement of existing single glazed window frames (transmittance equal to $5.53 \mathrm{~W} / \mathrm{m}^{2} \mathrm{~K}$ ) with double glazed window frames (transmittance equal to $1.70 \mathrm{~W} / \mathrm{m}^{2} \mathrm{~K}$ ) according to the limit required by legislation;

- installation of a photovoltaic or a solar cooling system.

The decision not to intervene on the walls was dictated by the fact that the building falls within the constraint of the historical and cultural heritage, while 
the alternative choice between the photovoltaic system and the solar cooling one is linked to constraints on the optimal surface coverage for the installation of the photovoltaic modules and the solar collectors.

\subsection{Photovoltaic system}

The Photovoltaic System, to be installed on the flat roof of the building, has a nominal power of $53.36 \mathrm{kWp}$ and is composed of polycrystalline silicon modules, with efficiency equal to $14.1 \%$ and nominal power equal to $230 \mathrm{~W}$.

The total number of modules, calculated taking into account the space available is 232 for a total area of approximately $380 \mathrm{~m}^{2}$.The provision on the roof is shown in Figure 8. The photovoltaic modules are divided into 16 strings of 13 modules and 2 strings of 12 modules. Their tilt inclination is $30^{\circ}$, the optimal choice for the locality of reference (Rome) which has a latitude of $41^{\circ}$ $56^{\prime}$, while the azimuth is $+22^{\circ}$.

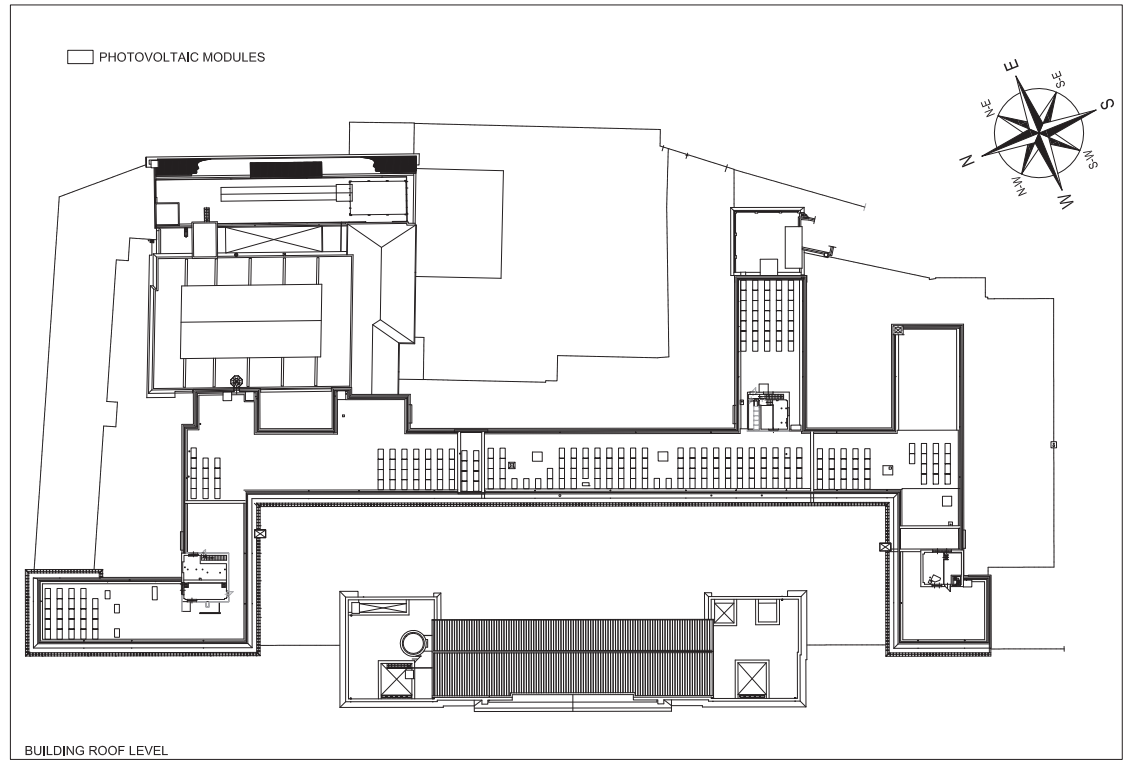

Figure 8: Photovoltaic system: location of the modules on the building rooftop.

In the calculation made, the annual energy $\left(E_{r e}\right)$ of system in terms of electricity is equal to:

$$
\mathrm{E}_{\mathrm{re}}=68.7 \frac{M W h}{y e a r} .
$$




\subsection{Solar cooling system}

A solar cooling system is able to produce summer conditioning through solar thermal energy. What makes the solar cooling system really interesting is the perfect time phase, which is obtained by using this technology, between the peak cooling demand and maximum availability of solar radiation (Figure 9).

The system has been designed by using software TRNsol which uses TRNsys 16 as simulator and its configuration is shown in Figure 10.

The plant has a $130 \mathrm{~kW}$ power and is composed of:

- Absorption Chiller with power of $130 \mathrm{~kW}$;

- Evacuated Tube Solar Collectors with an efficiency of $60 \%$ and a total surface area of approximately $380 \mathrm{~m}^{2}$;

- Hot Water Storage Tank with capacity of 2.000 liters;

- Auxiliary Hot Water Tank with capacity of 1.000 liters;

- Cold Tank with capacity of 2.000 liters;

- $\quad$ Temperature Control System with input temperature machine $85^{\circ} \mathrm{C}$ and output temperature machine $7^{\circ} \mathrm{C}$;

- Cooling Tower with a flow rate of approximately $13.500 \mathrm{~m}^{3} / \mathrm{h}$.

\subsection{Energy efficiency improvement: results}

Facing the same analysis in both steady state and transient, we find that the total heating energy demand in winter obtained is around $3 \mathrm{kWh} / \mathrm{m}^{3}$ year with a promotion from the energy point of view of the original structure from a " $D$ " class to an "A" Class.

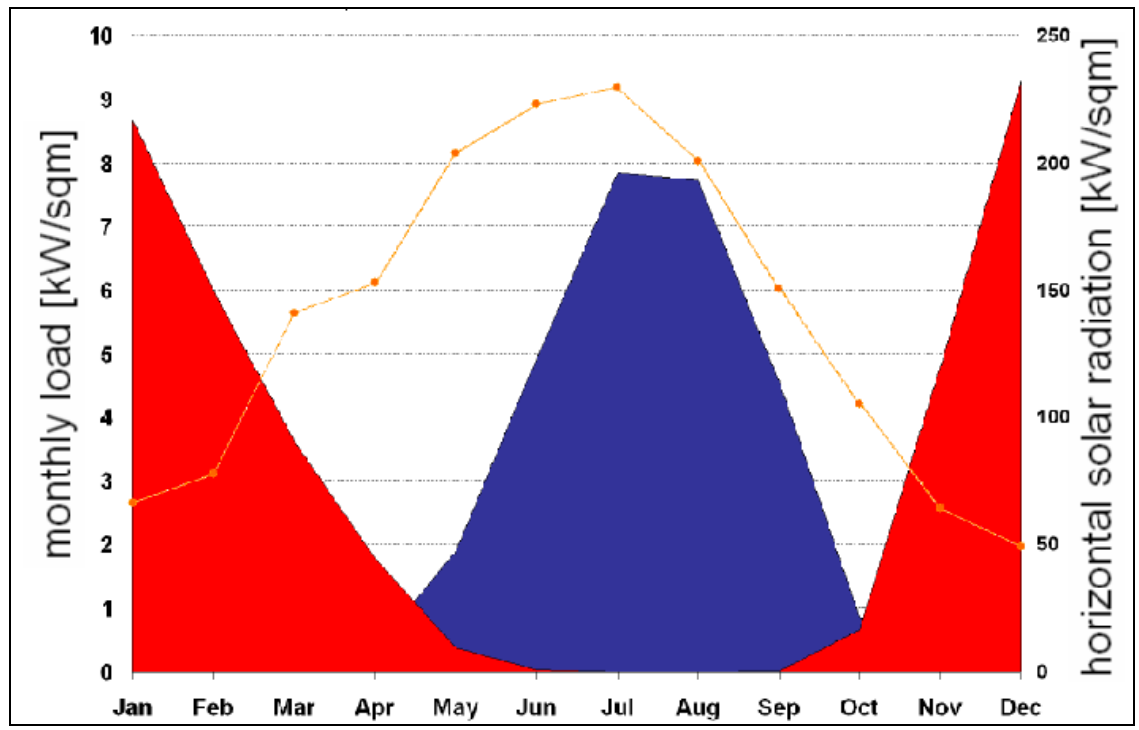

Figure 9: Monthly thermal loads and solar radiation comparison. 


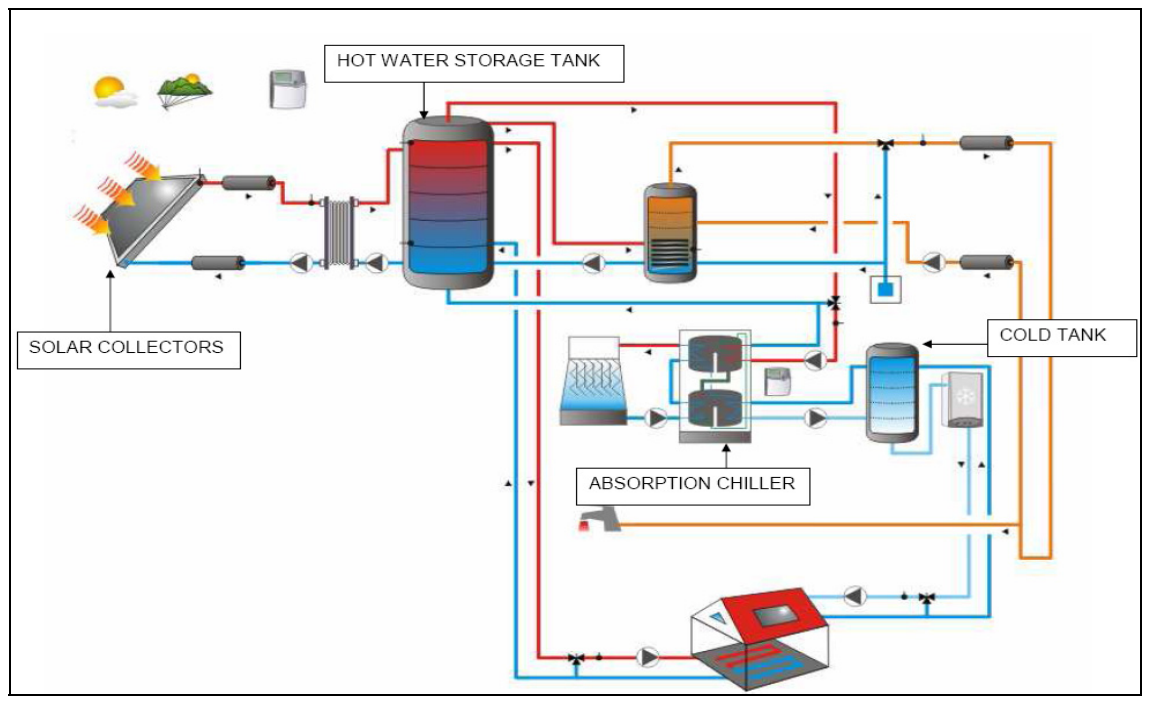

Figure 10: Solar cooling system: TRNsol simulation model.

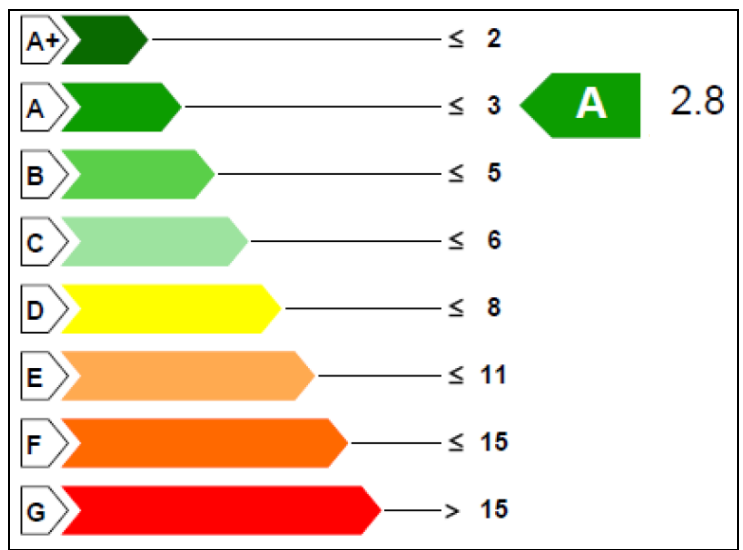

Figure 11: Building energy efficiency after energy efficiency improvement.

\section{Conclusions}

The study highlighted the importance of energy efficiency improvement of the buildings, which, for their great extension, consume a large amount of energy. These interventions, both structural and technological with the use of renewable sources, in many cases can improve significantly the energy performance and promote the building energy class in a higher level, as well illustrated in the case study proposed. However, in many cases, the economic factor takes great importance: for example, regarding to photovoltaic systems, the payback time is 
from 7 to 8 years while the solar cooling systems are not yet very encouraged in the energy saving policy, because their level of market placing is low because of the initial investment costs compared to a conventional air conditioning system. In contrast, however, is clear that these systems have almost zero electrical power consumption, according to the working principles of an absorption machine and they allow the use of solar energy when the cooling demand of confined spaces is highest: so they establish a perfect time phase between the maximum availability of renewable energy and the peak cooling demand.

\section{References}

[1] Hans, Martin, Henning: Solar Assisted Air Conditioning in Buildings A Handbook for Planners. Springer Wien/NewYork. 2nd revised edition 2008.

[2] Carvalho,MJ (2007), WP 4.5: SOLAR COOLING: Contribution to a future development of CTSS method applicable to solar assisted air conditioning systems (or solar cooling systems).

[3] TRNsys , Transient system simulation environment developed at the Solar Energy Laboratory at Univ. of Wisconsin, Madison, USA.

[4] STIMA10-TFM7, Steady State Simulation Software: User Manual, Watts Industries.

[5] GSE, Le Guide Blu, Impianti Fotovoltaici a norma CEI, 2008.

[6] Groppi, Zuccaro: Impianti Solari Fotovoltaici a norma CEI, 2008.

[7] Bartolazzi: Le Energie Rinnovabili, Milano, 2006.

[8] ENEA: Le fonti rinnovabili, 2003.

[9] Italian Legislation about Energy Saving. 